\title{
Small Bowel Obstruction: Epidemiological, Clinical and Therapeutic Aspects in the General Surgery Department of Hôpital Sominé DOLO de Mopti
}

\author{
Bréhima Traoré ${ }^{*}$, Modibo Coulibaly ${ }^{2 *}$ (), Djibril Traoré1, Oumar Guindo3, Fodé Mory Keita4, \\ Nouhoum Samassekou', Abdoulaye Traoré5, Souleymane Sanogo ${ }^{6}$, Korotimi Mallé1, \\ Kiffery Ibrahim Keita1, Pierre Coulibaly ${ }^{7}$, Aly Boubacar Dialloㅇ, Dramane Cissé1, \\ Dramane Samaké9, Lassana Kanté10
}

\begin{abstract}
${ }^{1}$ Department of General Surgery, Hôpital Sominé DOLO de Mopti, Mopti, Mali
${ }^{2}$ Department of Biomedical Laboratory, Hôpital Sominé DOLO de Mopti, Mopti, Mali

${ }^{3}$ Department of Public Health, Hôpital Sominé DOLO de Mopti, Mopti, Mali

${ }^{4}$ Department of Surgery, Polyclinique des armées, Kati, Mali

${ }^{5}$ Department of Anesthesia-Resuscitation, Hôpital Sominé DOLO de Mopti, Mopti, Mali

${ }^{6}$ Department of Medical Imagery CHU Luxembourg, Bamako, Mali

${ }^{7}$ Department of Gynecology-Obstetrics, Hôpital Sominé DOLO de Mopti, Mopti, Mali

${ }^{8}$ Department of Surgery, Hôpital de Sikasso, Sikasso, Mali

${ }^{9}$ Department of Medicine, Hôpital Sominé DOLO de Mopti, Mopti, Mali

${ }^{10}$ Department of General Surgery of CHU du Point-G, Bamako, Mali

Email: ^drbrehimat2@gmail.com, modibocoulibaly@yahoo.com,dtdjibsonl28@gmail.com, barugdo@yahoo.fr, keitaf70@yahoo.fr, nouxynsam@yahoo.fr, ngoaabdoulaye@yahoo.fr, letjou123@yahoo.fr, mallekoro@gmail.com, kifferyibrahim@gmail.com, coulipierre@yahoo.fr, dialloalyboubacar83@gmail.com,djennecisse@yahoo.fr, dramanesamake@rocketmail.com, kantelas@yahoo.fr
\end{abstract}

How to cite this paper: Traoré, B., Coulibaly, M., Traoré, D., Guindo, O., Keita, F.M., Samassekou, N., Traoré, A., Sanogo, S., Mallé, K., Keita, K.I., Coulibaly, P., Diallo, A.B., Cissé, D., Samaké, D. and Kanté, L. (2021) Small Bowel Obstruction: Epidemiological, Clinical and Therapeutic Aspects in the General Surgery Department of Hôpital Sominé DOLO de Mopti. Surgical Science, 12, 196-203. https://doi.org/10.4236/ss.2021.126021

Received: May 17, 2021

Accepted: June 26, 2021

Published: June 29, 2021

\begin{abstract}
Small bowel obstruction (SBO) is defined as a complete and persistent cessation of the transit of materials and gases. It occurs in a segment of the digestive tract located between the pylorus and the colorectal junction. We report an observational study which aims to describe the epidemiological, clinical and therapeutic aspects of small bowel obstruction. This study was carried out in the General Surgery Department of Hôpital Sominé DOLO de Mopti from October 1, 2016 to October 1, 2018. A total of 114 patients were recorded for whom the diagnosis was related to an occlusion. The median age was 37 years with extremes ranging from 6 months to 90 years. Male sex was predominant with a sex-ratio of 1.8. The frequency of small bowel occlusions over all occlusions was $74.03 \%$. The most encountered clinical signs were as followed: abdominal pain (100\%), vomiting (88.6\%), cessation of materials
\end{abstract}


Copyright $\odot 2021$ by author(s) and Scientific Research Publishing Inc. This work is licensed under the Creative Commons Attribution International License (CC BY 4.0).

http://creativecommons.org/licenses/by/4.0/ (c) (i) Open Access and gas (79.9\%) and meteorism (62.3\%). All patients underwent medical imaging, the most common of which was an abdomen without preparation $\mathrm{X}$-ray (AWP). On the etiological level, the main causes found postoperatively were: flanges and adhesion (55.2\%), strangulated hernias (28.0\%), acute intussusception (6.1\%), small bowel volvulus (3.5\%) and small bowel tumor (1.6\%). Releasing the bridles was the most common surgery process (28.0\%). The morbidity of the immediate follow-up was (13.1\%) and the mortality was (7.0\%). This high mortality is due to ignorance of the signs of seriousness and the socio-cultural barrier (decision of the patriarch to agree to a surgical intervention), the late use of hospital facility and the limited financial capability of the patients.

\section{Keywords}

Occlusions of the Small Intestine, Etiology, Surgical Treatment, Hôpital Sominé DOLO de Mopti

\section{Introduction}

Bowel obstruction is defined as a complete and persistent cessation of transit (materials and gases) in a segment of the digestive tract located between the pylorus and the colorectal junction [1]. They are the cause of $10.0 \%$ to $20.0 \%$ of acute abdominal pain in adults in general [2]. In Europe, bridle and adhesions were the etiology in $70.0 \%$ of cases with a non-negligible mortality of $4.0 \%$ to $17.0 \%$ depending on the series [3]. In the United States, Williams S.B. et al., found a death rate of $2.1 \%$ in 2001 in about 339 cases [4]. In Africa and Morocco, 128/191 (67.02\%) of cases of intestinal obstruction were in the small bowel, with an overall mortality of $7.85 \%$ according to Canis M. et al. [5]. Harouna et al., in Niger reported $39.36 \%$ of bowel obstruction in emergency department [6]. Dembélé B.T. et al. reported 659 acute intestinal obstructions, including 100 small bowel obstructions on flanges and adhesions, i.e. a frequency of $17.8 \%$ [7]. Acute small bowel obstruction (SBO) is a pathology whose character of extreme medical and surgical emergency has long been illustrated by the famous aphorism: "you should never let the sun rise and set on an intestinal obstruction" [3] [4] [8]. The most common cause of SBO is the development of adhesion, abdominal surgery or spontaneous flanges, which account for $50 \%$ to $80 \%$ of cases [4]. SBO diagnosis relies on the medical examination and medical imagery such as X-ray of the abdomen without preparation (AWP), abdomen ultrasonography and computed CT scan. These can be used respectively as the first-line examination, and by extension as a second-line, and thereby provide sufficient information necessary for conservative medical treatment or surgery decision-making process [5] [6]. Nevertheless, CT scan remains the goal standard, because it provides information on the cause, location, and especially the vitality of the loop [9]. SBO treatment is medico-surgical, the decision of conservative or surgical 
treatment remains a clinical challenge in a large number of cases [10]. Its prognosis depends on the early diagnosis and management. Herein, we discuss the epidemiology, diagnosis, clinical features and our experience in the management of SBO.

\section{Patients and Methods}

We carried out a prospective and retrospective observational study over two years from 2016-2018 at Hôpital Sominé DOLO de Mopti by successive recruitment. The diagnosis of the small bowel obstruction (SBO) was made by the help of surgeon physician examination, abdominal X-ray and was confirmed intraoperatively. Were included in this study all patients who underwent surgery for acute bowel occlusion at the general surgical department. Those whose diagnosis were not bowel occlusion at physical examination, medical imaging and postoperatively, and non-consenting patients were not enrolled in this study. As an observational study, subjects were enrolled by successive recruitment and the sample was set to 114 at the end of the study period. All patients gave the fully informed written consent prior to their enrollment. SBO frequency, etiology and the technique used during surgical intervention were the variables studied in this work. Data were collected from physical examination, surgery and hospitalization reports. Also the anatomopathological examination reports were recorded postoperatively for all subjects. Laparotomy and inguinotomy have been used as the initial surgical management. Resection of the bridle, resection anastomosis of the small bowel and adhesiolysis were the main used surgical techniques. Data were recorded in Microsoft Excel and then captured in Epi-info version 7.0 for analysis. Pearson $\mathrm{Ch} 2$ test was used for proportions comparison. P-value less than 0.05 was considered for having statistical significant.

\section{Results}

A total of 114 cases of SBO were identified in the department of general surgery of Hôpital Sominé DOLO de Mopti (Table 1). The mean age was 37 years with extremes ranging from 6 months to 90 years. SBO accounted for $7.52 \%$ (114/1514) of consultations, $8.27 \%$ (114/1378) of hospitalizations, $3.98 \%$ $(114 / 2866)$ of surgeries, and $74.03 \%$ (114/154) bowel occlusion (Table 2). Acute intestinal obstruction on an isolated bridle was found in $45.6 \%$ and occlusion on a bridle associated with adhesions was more frequent intraoperatively $(55.2 \%)$ of cases (Table 3). All of our patients were resuscitated before, during and postoperatively. General anesthesia with orotracheal intubation and antibiotic prophylaxis have been taken in all patients. The occlusion was on the ileum in $53.5 \%$ (Figure 1) and the loop was healthy in $81.6 \%$ of cases. Laparotomy was the most common route of entry in $81.6 \%$ of cases. The section of the bridle was the most performed procedure $(28.1 \%)$ followed by anastomosis resection in $18.4 \%$ of cases (Table 4). The average duration of the intervention was $97 \mathrm{mi}-$ nutes with extremes ranking from $35 \mathrm{~min}$ to $206 \mathrm{~min}$. The immediate postopera- 
tive effects were straightforward in $86 \%$ of cases. The most common postoperative morbidity was surgical site infection in $8.8 \%$ of cases. Mortality was 8 cases (7.0\%) of cases. The average length of hospital stay was 8 days with extremes ranging from 3 days to 45 days. Patients with necrotic bowel loops died in $87.5 \%$ (7/8). Mortality was higher in patients in whom we performed an anastomosis resection in one step (18.2\%).

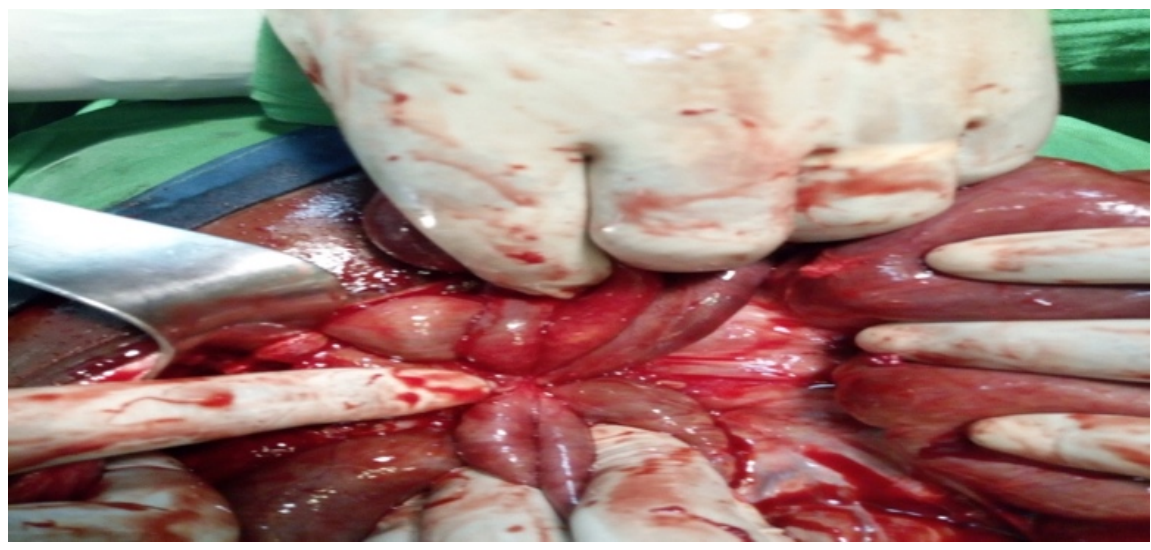

Figure 1. Occlusion on the ileo-ileal flange. Hôpital Sominé Dolo de Mopti.

Table 1. Distribution of patients according to surgical techniques.

\begin{tabular}{ccc}
\hline \multirow{2}{*}{ Surgical technique } & \multicolumn{2}{c}{ Table Column Head } \\
\cline { 2 - 3 } Bridle resection & Number & Pour cent \\
\hline Small bowel anastomosis resection & 32 & 28.0 \\
Adhesiolysis & 21 & 18.4 \\
Aponeuropathy treatment & 15 & 13.2 \\
Cure according to Bassini & 14 & 12.2 \\
Cure according to shouldice & 13 & 11.4 \\
Ostomy & 8 & 7.0 \\
Extrication & 7 & 6.1 \\
Disinvagination & 2 & 1.8 \\
Total & 2 & 1.8 \\
\hline
\end{tabular}

Table 2. Frequency of small bowel obstructions (SBO) across all intestinal obstructions.

\begin{tabular}{cccc}
\hline \multirow{2}{*}{ Authors/SBO frequencies } & \multicolumn{3}{c}{ Table Column Head } \\
\cline { 2 - 4 } & Number & Pour cent & p-value \\
\hline Arnold et al., France 2003 [11] & 131 & 32.00 & $<0.001$ \\
Mehmet U. et al., Maroc 2012 [13] & 128 & 67.02 & 0.25 \\
Kurem R.T. et al., Pakistan 2014 [12] & 102 & 54.55 & 0.24 \\
Our study & 114 & 74.03 & \\
\hline
\end{tabular}


Table 3. Comparison of the etiologies found.

\begin{tabular}{cccccc}
\hline & \multicolumn{5}{c}{ Table Column Head } \\
\cline { 2 - 6 } Etiology/Authors & $\begin{array}{c}\text { Adhesion } \\
\mathrm{N}(\%)\end{array}$ & $\begin{array}{c}\text { Bridle } \\
\mathrm{N}(\%)\end{array}$ & $\begin{array}{c}\text { Adhesion-bride } \\
\mathrm{N}(\%)\end{array}$ & $\begin{array}{c}\text { Hernia } \\
\mathrm{N}(\%)\end{array}$ & $\begin{array}{c}\text { Tumor } \\
\mathrm{N}(\%)\end{array}$ \\
\hline Goussous et al., USA 2015 & $84(56.0)$ & $0(0.0)$ & $0(0.0)$ & $32(26.9)$ & $7(5.0)$ \\
Kouadio et al., RCI 2001 [10] & $7(14.3)$ & $39(79.5)$ & $3(6.8)$ & $0(0.00)$ & $0(0.0)$ \\
Miller et al., Canada 2005 [22] & $200(22.0)$ & $102(25.0)$ & $106(26.0)$ & $0(0.00)$ & $0(0.0)$ \\
Harouna et al., Niger 2005 [6] & $0(0.0)$ & $72(82.8)$ & $15(38.6)$ & $0(0.00)$ & $0(0.0)$ \\
Mehmet U. et al., Maroc 2012 [13] & $38(30.0)$ & $0(0.0)$ & $14(11.0)$ & $67(52.0)$ & $9(7.0)$ \\
Our Study & $11(9.6)$ & $52(45.6)$ & $63(55.2)$ & $21(18.4)$ & $2(1.6)$ \\
\hline
\end{tabular}

Table 4. Comparison of the surgical techniques used.

\begin{tabular}{|c|c|c|c|c|}
\hline \multirow[b]{2}{*}{ Authors } & \multicolumn{3}{|c|}{ Table Column Head } & \multirow[b]{2}{*}{$\begin{array}{c}\text { Anastomosis } \\
\text { Resection } \\
\text { N (\%) }\end{array}$} \\
\hline & $\begin{array}{c}\text { Bridle resection } \\
\text { N (\%) }\end{array}$ & $\begin{array}{l}\text { Ostomy } \\
\mathrm{N}(\%)\end{array}$ & $\begin{array}{c}\text { Adhesiolysis } \\
\mathrm{N}(\%)\end{array}$ & \\
\hline Kouadio et al., CI 2001 [10] & $25(51.0)$ & $0(0.0)$ & $5(10.2)$ & $17(34.7)$ \\
\hline Beyrout et al., Tunisie 2006 [18] & $152(59.0)$ & $0(0.0)$ & $54(21.1)$ & $30(11.6)$ \\
\hline Our study & $32(28.1)$ & $7(6.1)$ & $15(13.2)$ & $21(18.4)$ \\
\hline
\end{tabular}

\section{Discussion}

We conducted a prospective and retrospective observational study from 2016 to 2018 at the general surgery department of Hôpital Sominé DOLO de Mopti. A total of 114 cases of SBO was enrolled in this study, 53 prospectively and 61 retrospectively. We found (114/154) or $74.03 \%$ of SBO. This rate was higher than that of Arnold PB et al., 2000 [11]. This difference could be explained by the rarity of bridle occlusions in the French series due to the contribution of minimally invasive surgery (laparoscopy). In contrast, our result does not differ statistically from those of the Pakistani and Moroccan series [12] [13], p-value $>0.05$.

The age is discussed to be or not considered as a risk factor for SBO [11], we found no difference in term of age between our series and those from Russia and Côte d'Ivoire. However, it was significantly lower than that of French series [11], $\mathrm{p}$-value $=0.003$. This could be explained by the youth of the African population in general and Malian in particular [7]. The gender influence on the occurrence of SBO is also discussed, however in our study as well as in the other series [6] [10] [14] the majority of patients were represented by men. The 28-day consultation period of our study is statistically comparable to those of the Japanese and French series [15] [16] with p-value $=0.05$. On the other hand, it is lower than that of Beyrout in Tunisia [17], p-value $<0.05$. Occlusion syndrome is the main symptom of SBO [16]. The proportion of $18.4 \%$ of occlusive syndrome in our study is significantly lower than those of the Japanese, French and Tunisian series which respectively reported $100.0 \%, 50.0 \%$ and $57.0 \%$, all p-value $<0.05$. 
This difference could due to the inconsistency of certain signs of SBO such as abdominal distension, stopping of materials and gas in our study. Abdominal pain and vomiting are very common symptoms of SBO [18]. Abdominal pain was observed in all of our patients and in all other series [6] [10] [14]. The proportion of vomiting and cessation of materials in our study were $88.6 \%$ and $79.8 \%$, respectively. These proportions did not differ from those of other African series [6] [14]. The abdominal X-ray (ASP) is the first-line examination followed by abdomen ultrasonography and CT scan for any suspicion of small bowel obstruction [19] [20], in our study, abdomen X-ray was performed in 95.6\%. This proportion was in line with those of the other African series [6] [10] [14]. When it happens to deal with SBO, the surgical procedure depends on the condition of the loops, the etiology and the hemodynamic condition of the patient. The section of the bridle was the most performed surgical procedure in our series with $28.1 \%$. This proportion was significantly different from those of Kouadio and Beyrout [10] [17] p-value $<0.05$. This difference could be explained by the condition of the loop and other associated lesions in our series. Adhesiolysis and anastomosis resection were performed in $13.2 \%$ and $18.4 \%$, respectively in our study. The proportion of adhesiolysis in our series did not differ from those reported by Kouadio and Beyrout [10] [17]. We have performed ileostomy in 6.1\% unlike the other series [10] [17]. The high proportion of ileostomy in our series can be explained by the delay in patients' management, itself linked to the delay in seeking medical facilities. The bridle and adhesion were the most frequent etiologies in our study $55.2 \%$ which was higher than that of the other series [6] [10] [14] [21] with a p-value $<0.05$. This difference could be related to the sample size, medical and surgical history. Morbidity in our study was $13.2 \%$ and was dominated by surgical site infection with a rate of $8.8 \%$. This was comparable to those reported by the Ivorian and French authors [10] [22] with p-value $>0.05$. However, we found a significant difference with the Tunisian, American and Japanese series [17] [20] [23], p-value $<0.05$. This difference could be related to the surgical technique, the age and the general condition of our patients. The average length of hospital stay in our series was 8 days. This hospital stay was comparable to that reported by Arnold P.B. et al. [11], p-value >0.05. However, it is lower than that reported by Harouna et al. [6]. This difference could be linked to the high number of postoperative complications in their series.

\section{Conclusion}

$\mathrm{SBO}$ is a medico-surgical emergency that requires early management to improve the prognosis. In Africa, it often affects very young population and occurs most frequently after an inflammatory process in the abdominal cavity even in the absence of history of surgery. The delay in seeking medical facilities and the advanced age of the majority of these patients make the seriousness of this pathology. Despite the multiplicity of diagnostic, therapeutic and surgery modalities, morbidity and mortality still remain high. 


\section{Acknowledgements}

We are grateful to all patients of this study; the staff of Mopti Hospital, Hôpital Sominé DOLO de Mopti, Mali, Academic Hospital Hôpital Point-G, Bamako, Mali for their assistance.

\section{Statement of Informed Consent}

The patients gave fully informed written consent prior to this publication.

\section{Conflicts of Interest}

The authors declare no conflicts of interest regarding the publication of this paper.

\section{References}

[1] Weibel, M.-A. and Majno, G. (1973) Peritoneal Adhesions and Their Relation to Abdominal Surgery. A Postmortem Study. The American Journal of Surgery, 126, 345-353. https://doi.org/10.1016/S0002-9610(73)80123-0

[2] Parker, M.C., Ellis, H., Moran, B.J., Thompson, J.N., Wilson, M.S., Menzies, D., McGuire, A., Lower, A.M., Hawthorn, R.J., O’Briena, F., Buchan, S. and Crowe, A.M. (2001) Postoperative Adhesions: Ten-Year Follow-Up of 12,584 Patients Undergoing Lower Abdominal Surgery. Diseases of the Colon \& Rectum, 44, 822-829. https://doi.org/10.1007/BF02234701

[3] Menzies, D. (1992) Peritoneal Adhesions. Incidence, Cause, and Prevention. Surgery Annual, 24, 27-45. https://pubmed.ncbi.nlm.nih.gov/1727325

[4] Williams, S.B., Greenspon, J., Young, H.A. and Orkin, B.A. (2005) Small Bowel Obstruction: Conservative vs. Surgical Management. Diseases of the Colon \& Rectum, 48, 1140-1146. https://doi.org/10.1007/s10350-004-0882-7

[5] Canis, M., Botchorishvili, R., Wattiez, A., Rabischong, B., Houlle, C., Mage, G., Pouly, J.L., Manhes, H. and Bruhat, M.A. (2001) Prévention des adhérences péritonéales. Journal de Gynécologie Obstétrique et Biologie de la Reproduction, 30, 305-324. https://pubmed.ncbi.nlm.nih.gov/11431609

[6] Harouna, Y., Maazou, I., Almoustapha, I., Samir, R., Amadou, S., Baoua, A., et al. (2005) Les occlusions intestinales aigues par brides: A propos de 87 cas. Médecine d Afrique Noire, 935, 317-319.

[7] Dembélé, B.T., Traoré, A., Diakité, I., Kanté, L., Togo, A., Maiga, A., Diarra, M.B., Coulibaly, Y., Kéita, M., Diango, D.M. and Diallo, G. (2011) Occlusion du grêle sur bride et adhérence en chirurgie générale CHU Gabriel Touré, Département de chirurgie générale CHU Gabriel Touré. Mali Medical, 26, 12-15. https://pubmed.ncbi.nlm.nih.gov/22765951

[8] La Gamma, A., Letoquart, J.P., Kunin, N., et al. (1994) Les occlusions du grêle par brides et adhérences. Analyse sur 157 Cas opérés. Journal de Chirurgie, 131, 279-284. https://pubmed.ncbi.nlm.nih.gov/7844179

[9] Raftery, A.T. (1973) Regeneration of Parietal and Visceral Peritoneum: An Electron Microscopical Study. Journal of Anatomy, 115, 375-392. https://pubmed.ncbi.nlm.nih.gov/4762132

[10] Kouadio, G.K. and Turquin, H.T. (2004) Prise en charge des occlusions post-opératoires du grêle par brides et adhérences au CHU de Treichville à Abidjan. Médecine 
d Afrique Noire, 51, 629-632.

http://www.santetropicale.com/manelec/fr/resume oa.asp?id article=160\#haut

[11] Arnold, P.B., Green, C.W., Foresman, P.A. and Rodeheaver, G.T. (2000) Evaluation of Resorbable Barriers for Preventing Surgical Adhesions. Fertility and Sterility, 73, 157-161. https://doi.org/10.1016/S0015-0282(99)00464-1

[12] Kuremu, R.T. and Jumbi, G. (2006) Adhesive Intestinal Obstruction. East African Medical Journal, 83, 333-336. https://doi.org/10.4314/eamj.v83i6.9441

[13] Mehmet, U., Ismail, A., Gürkan, Y., Abut, K., Adnan, I. and Aziz, S. (2004) Factors Affecting Morbidity and Mortality in Mechanical Intestinal Obstruction. Ulus Travma Acil Cerrahi Derg, 10, 177-184. https://pubmed.ncbi.nlm.nih.gov/15286889

[14] Edna, T.-H. and Bjerkeset, T. (1998) Small Bowel Obstruction in Patients Previously Operated on for Colorectal Cancer. European Journal of Surgery, 164, 587-592. https://doi.org/10.1080/110241598750005688

[15] Habib, E. and Elhadad, A. (2003) Occlusion de l'intestin grêle sur bride congénitale chez 16 adultes. Annales de Chirurgie, 128, 94-97.

https://doi.org/10.1016/S0003-3944(02)00037-8

[16] Hirotada, K., Hiroshi, A., Hitoshi, T., Hiroyuki, F., Hiroshi, H., Masao, O., Hitoshi, K. and Yasuo, O. (2014) Usefulness of Intestinal Fatty Acid-Binding Protein in Predicting Strangulated Small Bowel Obstruction. PLoS ONE, 9, e99915. https://doi.org/10.1371/journal.pone.0099915

[17] Beyrout, I.M., Gargouri, F., Gharbi, A., Beyrouti, R., Fki, I., Dhieb, N., Amar, B.M., Abid, M., Masmoudi, A., Ghorbel, A. and Sellami, A. (2006) Late Post-Operative Adhesive Small Bowel Occlusions. About 258 Cases. La Tunisie Medicale, 84, 9-15. https://pubmed.ncbi.nlm.nih.gov/16634206/

[18] Maglinte, D.D., Gage, S.N., Harmon, B.H., Kelvin, F.M., Hage, J.P., Chua, G.T., Ng, A.C., Graffis, R.F. and Chernish, S.M. (1993) Obstruction of the Small Intestine: Accuracy and Role of CT in Diagnosis. Radiology, 188, 61-64. https://doi.org/10.1148/radiology.188.1.8511318

[19] Delabrousse, E., Saguet, O., Destrumelle, N., et al. (2001) Sigmoid Volvulus: Value of CT. Journal de Radiologie, 82, 930-932.

https://pubmed.ncbi.nlm.nih.gov/11604692

[20] Megibow, A.J., Balthazar, E.J., Cho, K.C., Medwid, S.W., Birnbaum, B.A. and Noz, M.E. (1991) Bowel Obstruction: Evaluation with CT. Radiology, 180, 313-318. https://doi.org/10.1148/radiology.180.2.2068291

[21] Miller, G., Boman, J., Shrier, I. and Gordon, P.H. (2000) Etiology of Small Bowel Obstruction. The American Journal of Surgery, 180, 33-36. https://doi.org/10.1016/S0002-9610(00)00407-4

[22] Duron, J., Keilani, K., Barrat, C., et al. (1996) Contamination per-opératoire de la cavité péritonéale par des micros étrangers. Chirurgie, 121, 175-180. https://pubmed.ncbi.nlm.nih.gov/8945822/

[23] Hashimoto, D., Hirota, M., Matsukawa, T., Yagi, Y. and Baba, H. (2002) Clinical Features of Strangulated Small Bowel Obstruction. Surgery Today, 42, 1061-1065. https://doi.org/10.1007/s00595-012-0207-8 